\title{
Nueva deducción del derecho natural
}

Friedrich Wilhelm Joseph Schelling

Traductor: Faustino Oncina Coves

\section{OpenEdition}

\section{Journals}

Edición electrónica

URL: http://journals.openedition.org/ref/405

DOI: $10.4000 /$ ref.405

ISSN: 2258-014X

Editor

EuroPhilosophie Editions

Referencia electrónica

Friedrich Wilhelm Joseph Schelling, « Nueva deducción del derecho natural », Revista de Estud(i)os sobre Fichte [En línea], 3 | 2011, Publicado el 01 febrero 2011, consultado el 08 septiembre 2020. URL http://journals.openedition.org/ref/405 ; DOI : https://doi.org/10.4000/ref.405

Este documento fue generado automáticamente el 8 septiembre 2020.

(c) EuroPhilosophie 


\title{
Nueva deducción del derecho natural
}

\author{
Friedrich Wilhelm Joseph Schelling \\ Tradución : Faustino Oncina Coves
}

\section{NOTA DEL AUTOR}

Es menester dejar constancia de la génesis de esta traducción, pues es la secante de dos proyectos inicialmente convergentes, pero ulteriormente divergentes. Margarita Vicedo realizó una versión, aunque incompleta, para su tesis de licenciatura. Yo hice lo mismo, en posesión ya de la edición histórico-crítica de la obra de Schelling -a la sazón todavía en estado naciente- para mi tesis doctoral y, merced a una estancia en el MaxPlanck-Institut für europäische Rechtsgeschichte de Fráncfort del Meno y en el KantArchiv de la Universidad de Maguncia, con miras a la preparación de una antología de artículos sobre filosofía del derecho de la década 1790-1800, espoleados la mayoría por la Revolución Francesa y escritos bajo la égida del Criticismo. Las versiones citadas han sido cuidadosamente cotejadas y revisadas por mí, y mía es, en consecuencia, la responsabilidad última, sobre todo en lo tocante a los posibles errores. Además, he creído conveniente añadir algunas notas aclaratorias tanto en el plano filológico, como en el de las fuentes históricas. Las cifras entre corchetes, intercaladas en la traducción, indican la paginación del texto alemán FRIEDRICH WILHELM JOSEPH SCHELLING. Historischkritische Ausgabe, I/3, edición a cargo de H. BUCHNER, W. G. JACOBS y A. PIEPER, Frommann, Stuttgart, 1982. También ha sido consultada la edición de Manfred Schröter: Schellings Werke, Erster Hauptband, Beck, Múnich, 1927 (3ª ed. 1979). Las notas a pie de página son del propio Schelling; las llamadas entre paréntesis corresponden a notas del traductor. (F. Oncina).

[139] 


\section{Deducción de la ciencia del derecho en general y de su principio supremo}

§ 1 Lo que no puedo realizar teóricamente, debo realizarlo prácticamente. Ahora bien, la razón aspira a lo incondicionado, que es inalcanzable por la razón teórica, pues no puede devenir nunca objeto para mí. En cuanto quiero aprehenderlo como objeto, retrocede a los límites de lo condicionado. Lo que es objeto para mí, sólo puede aparecer fenoménicamente; tan pronto como para mí sea más que fenómeno, queda aniquilada mi libertad.

$\S 2$ Si debo realizar lo incondicionado, entonces tiene que dejar de ser objeto para mí. He de pensar el ser último que sirve de fundamento a todo lo que existe, el ser absoluto que se revela en toda existencia, como idéntico a mí mismo, a lo que hay de último e inmutable en mí.

$\S 3$ ¡Sé! en el sentido más elevado de la palabra. ¡Deja de ser tú mismo fenómeno! ¡Esfuérzate por devenir un ser en sí! Ésta es la exigencia suprema de toda filosofía práctica.

$\S 4 \mathrm{Si}$ eres un ser en sí, ninguna potencia (Macht) contraria puede cambiar tu estado (Zustand), ni limitar tu libertad. Luego esfuérzate [140] por devenir un ser en sí, por ser absolutamente libre, esfuérzate por someter a tu autonomía (Autonomie) toda potencia heterónoma; esfuérzate, mediante la libertad, por desplegar tu propia libertad hasta lograr una potencia absoluta e ilimitable.

$\S 5$ Este mandato es incondicionado (unbedingt), porque exige un incondicionado (Unbedingtes). Por tanto, el esfuerzo (Streben) que exige debe ser también incondicionado, es decir, dependiente sólo de sí mismo y no determinable por ninguna ley extraña.

§ 6 Si mi esfuerzo no debe ser determinable en absoluto por una ley extraña, entonces, a la inversa, todo lo que se le opone a mi esfuerzo, tiene que ser determinado simplemente por mi esfuerzo. Proclamándome ser libre, me proclamo un ser que determina todo lo que se le opone, pero él mismo no es determinable por nada.

$\S 7$ Domino sobre el mundo de los objetos; en él no se revela ninguna otra causalidad salvo la mía. Me proclamo señor de la naturaleza y exijo que esté determinada enteramente por la ley de mi voluntad. Mi libertad relega todo objeto a los límites del fenómeno, y precisamente por eso le prescribe leyes que no puede transgredir. Sólo al Yo (Selbst) inmutable le corresponde autonomía; todo lo que no es este Yo -todo lo que puede devenir objeto- es heterónomo, es fenómeno para mí. El mundo entero es mi propiedad moral (1).

§ 8 Si debo dominar el mundo de los fenómenos y regir la naturaleza según leyes morales, la causalidad de la libertad debe entonces [141] revelarse (offenbaren) ${ }^{1}$ a través de la causalidad física. La libertad en general sólo puede proclamarse mediante la autonomía originaria. Así pues, esta causalidad física, aunque heterónoma según el objeto-esto es, determinable sólo por leyes de la naturaleza-, sin embargo, debe ser autónoma según su principio -esto es, inalcanzable por medio de una ley de la naturaleza-. Debe reunir en sí autonomía y heteronomía.

§ 9 Esta causalidad se llama vida. La vida es la autonomía en el fenómeno, el esquema de la libertad, en tanto que se revela en la naturaleza. Devengo por eso necesariamente un ser viviente. 
§ 10 Hasta donde alcanza mi potencia física, doy mi forma a todo lo que existe, le impongo mis fines, lo utilizo como medio de mi voluntad ilimitada.

§ 11 Donde no basta mi potencia física, sólo hay resistencia (Widerstand) física; no puede haber para mí ninguna resistencia moral en la naturaleza. Lo que es físicamente imposible, sin embargo, es moralmente real, y, aunque lo que es moralmente real pueda ser físicamente imposible, en el mundo moral mi acción es realizada.

$\S 12$ La naturaleza está allí donde mi potencia física encuentra resistencia. Reconozco la superioridad de la naturaleza sobre mi fuerza (Kraft) física: como ser sensible me inclino ante ella, no puedo hacer más.

[142] § 13 Donde mi potencia moral encuentra resistencia, ya no puede haber naturaleza. Trémulo, me quedo quieto. ¡Aquí está la humanidad!, pregonan a gritos frente a mí. No me está permitido (darf) hacer más.

§ 14 En su falta de límites mi libertad puede ser pensada sólo como una potencia que anula toda causalidad contraria. Por consiguiente, donde cesa de ser ilimitada, debe erigirse frente a ella otra causalidad incondicionada.

$\S 15$ En cuanto siento limitada mi libertad, reconozco que no estoy solo en el mundo moral, y diversas experiencias de libertad limitada me enseñan que estoy ${ }^{2}$ en un reino de seres morales a quienes corresponde, a todos ellos, esta misma libertad sin límites.

$\S 16$ Esta causalidad carece de límites precisamente porque en ningún lugar tiene ante sí su propio fin, porque su meta no está determinada objetivamente en ninguna parte. Tiende a lo incondicionado, pero no lo presupone, sino que se esfuerza sólo por realizarlo mediante una acción infinita.

[143] § 17 Su fin último no es objetivo, por consiguiente, no es empírico. Pero como se esfuerza por alcanzarlo sólo en una serie temporal infinita, su esfuerzo es empírico.

$\S 18$ Aunque el fin último de todos los seres morales es intelectual y, en consecuencia, idéntico, su esfuerzo, en tanto que esfuerzo empírico (\$ 17), no es idéntico.

§ 19 Si todos los seres morales hubiesen alcanzado el fin supremo, su causalidad sería única e idéntica, no habría ningún conflicto (Widerstreit), sino una concordancia absoluta.

$\S 20$ Pero puesto que todos se esfuerzan por alcanzarlo sólo en el tiempo, su causalidad es tan diversa (no idéntica) como los objetos del mundo empírico.

$\S 21$ Luego la causalidad incondicionada de los seres morales deviene conflictiva en el esfuerzo empírico y comienzo a oponer mi libertad a la libertad de todos los demás.

$\S 22$ Sólo en tanto que pienso mi libertad en conflicto con otras causalidades iguales a ella, deviene ésta mi causalidad, es decir, una causalidad que no es la de los seres morales en general (del mundo moral en su conjunto). Llego a ser así individuo moral.

§ 23 No puedo (kann) dejar de afirmar mi libertad hasta que no sea satisfecha la exigencia: “ ¡Esfuérzate en pos de lo incondicionado!”. Pero no puedo afirmar mi libertad sin oponerla a la vez a la libertad de otros, en tanto que ésta colisiona con la mía en el esfuerzo empírico. Por consiguiente, la individualidad (Individualität) de mi voluntad está sancionada por aquella exigencia suprema de la razón práctica.

[144] § 24 Pero precisamente esta exigencia se dirige a todos los seres morales. Todo ser moral no debe (soll), sino que necesariamente tiene que $(\mathrm{mu} ß)$ permanecer individuo hasta que haya cumplido aquella exigencia. 
§ 25 Pero resulta imposible que todo ser moral afirme su libertad mientras la libertad incondicionada de los seres morales sea contradictoria en su esfuerzo empírico.

$\S 26$ Aunque la causalidad absoluta, pensada puramente, nunca puede contradecirse, sin embargo, la causalidad empírica absoluta de uno anula (hebt auf) toda causalidad empírica del otro. La actividad empírica ilimitada de uno pone pasividad empírica ilimitada en el otro.

$\S 27$ Todo ser moral debe afirmar su libertad en general (überhaupt). Pero esto no es posible más que si todo ser moral renuncia a la libertad empírica ilimitada. En efecto, la libertad empírica ilimitada conduce a un conflicto infinito en el mundo moral (\$ 26).

§ 28 Todo ser moral debe abandonar su libertad empírica sin límites para salvar su libertad en general; debe dejar de manifestarse como individuo por su esfuerzo, en tanto que empírico, para afirmase como tal por su esfuerzo en general.

§ 29 Imaginemos que todos los seres morales se esfuerzan por afirmar su propia individualidad; este esfuerzo universal de todos los seres morales en pos de la individualidad en general debe entonces limitar el esfuerzo de cada ser moral particular en pos de la individualidad empírica, [145] de tal manera que el esfuerzo empírico de todos los demás pueda coexistir con el suyo.

$\S 30$ Imaginemos que todos los seres morales quieren (wollen) en general; este querer universal de todos los seres morales debe entonces limitar el querer empírico de cada individuo particular, de tal modo que el querer de todos los demás pueda al mismo tiempo coexistir con el suyo.

§ 31 Aquí pasamos desde el terreno de la moral (Moral) al de la ética (Ethik). La moral en general establece un mandato (Gebot) que se dirige sólo al individuo y no exige más que la ipseidad (Selbstheit) absoluta del individuo; la ética establece un mandato que presupone un reino de seres morales y asegura la ipseidad de todos los individuos mediante la exigencia (Forderung) que dirige al individuo.

$\S 32$ Por tanto, el mandato de la ética no debe contener la expresión de la voluntad individual, sino la de la voluntad universal (allgemeinen Willens) (3).

$\S 33$ Pero este mandato de la ética (\$32) depende únicamente del mandato más elevado de la moral (\$ 3). La ética establece la voluntad universal como ley sólo para garantizar la voluntad individual mediante la universal. No reclamo mi individualidad porque me someto a la voluntad universal, sino que, por el contrario, me someto a la voluntad universal porque pretendo conquistar mi individualidad. La voluntad universal está condicionada por la individual, no la individual por la universal.

§ 34 Aquello que determina la voluntad universal es la forma de la voluntad individual (libertad) en general, prescindiendo de toda materia del querer. [146] Por consiguiente, la materia de la voluntad universal está determinada por la forma de la voluntad individual, y no a la inversa.

§ 35 La forma de la voluntad universal es la libertad en general, la materia es la moralidad (Moralität). Luego la libertad no depende de la moralidad, sino la moralidad de la libertad. No porque y en tanto que soy moral, soy libre; sino que, porque y en tanto que quiero ser libre, debo ser moral.

$\S 36 \mathrm{El}$ problema de toda ética es el siguiente: conservar la libertad del individuo mediante la libertad universal, la voluntad individual mediante la universal, o (puesto que la voluntad del individuo puede contradecir la de los demás sólo en cuanto deviene 
empírica (material)) hacer concordantes la voluntad empírica de todos y la voluntad empírica del individuo.

§ 37 Si me pienso como individuo en oposición a todos los demás, se plantea entonces la cuestión de si la voluntad empírica de todos los otros debe llegar a ser idéntica a mi voluntad o si mi voluntad individual debe llegar a ser idéntica a la de todos los otros.

$\S 38$ Si la voluntad de todos los demás debe llegar a ser idéntica a mi voluntad como tal, anulo con ello la voluntad de todos los otros como individuos, esto es, la voluntad universal no está condicionada por la voluntad individual (§33); el supuesto se contradice a sí mismo.

$\S 39 \mathrm{Si}$, a la inversa, mi voluntad, en cuanto es voluntad individual, debe ser determinada por la voluntad de todos los demás, la voluntad individual está entonces condicionada por la universal; lo que es nuevamente imposible (\$ 33 ).

$\S 40$ Luego no puede darse ninguno de los casos o deben darse ambos. Pero ambos pueden darse sólo si la voluntad del individuo [147] y la voluntad de todos (Wille Aller) son conceptos recíprocos, es decir, si la voluntad de todos es al mismo tiempo la voluntad del individuo y la voluntad del individuo es al mismo tiempo la voluntad de todos (4).

$\S 41$ Sólo merced a que la voluntad individual y la voluntad universal devienen conceptos recíprocos, cumplo la condición bajo la que se da únicamente un mandato ético (§33). No debo obrar como obran todos los demás; sino, inversamente, es como yo obro que deben obrar todos los demás. Pero para que todos los otros obren como yo lo hago, debo obrar como todos los otros pueden hacerlo. Sólo por la adhesión de la voluntad de todos los demás a la mía, se torna mi voluntad la voluntad de todos; sólo por la adhesión de mi voluntad a la voluntad de todos los demás, su voluntad deviene la voluntad de cada individuo, de la misma manera que la unidad sólo por la adición de la pluralidad, y la pluralidad sólo por la adición de la unidad, devienen universalidad.

$\S 42$ Sólo en cuanto pienso la voluntad en general como originariamente absoluta (absolut), puedo pensar la voluntad de todos los demás como limitada a la condición de la mía, y la mía como limitada a la condición de la voluntad de todos los demás. Por consiguiente, la limitación de la voluntad individual por medio de la voluntad universal presupone la ausencia de límites originarios de la voluntad.

$\S 43$ Sólo en cuanto limito mi voluntad a la condición de la voluntad de todos los demás y la voluntad de todos los demás a la condición de la mía, puedo pensar la voluntad en general como absoluta, y el problema de la voluntad absoluta, tal como lo plantea la moral, se resuelve en la ética merced a la concordancia (Übereinstimmung) universal de la voluntad de todos los individuos.

$\S 44 L a$ voluntad individual está entonces limitada por la voluntad universal sólo en cuanto se convierte en absoluta mediante esta limitación, y es [148] absoluta sólo en cuanto está limitada a la condición de la voluntad universal.

$\S 45 \mathrm{El}$ mandato supremo de toda ética reza así: obra de tal modo que tu voluntad sea voluntad absoluta; obra de tal modo que el mundo moral entero pueda querer tu acción (según su materia y su forma); obra de tal modo que mediante tu acción (según su contenido y su forma) ningún ser racional sea puesto como mero objeto, sino como sujeto cooperante (mithandelndes).

$\S 46$ En cuanto obro conforme a esta ley, reniego de mi individualidad; es decir, dejo de oponer mi libertad a la libertad de otros seres morales. Pero dejo de oponer mi libertad 
a la de otros seres morales sólo para que, inversamente, éstos dejen de oponer su libertad a la mía.

$\S 47$ Puesto que la voluntad universal está condicionada por la individual ( $\$ 33)$, y no a la inversa, la voluntad universal también puede determinar la materia de mi acción sólo en cuanto está condicionada por la voluntad individual, esto es, puedo someterme a la voluntad universal sólo en cuanto mediante ella afirmo la voluntad individual.

$\S 48$ Puesto que en general me pienso como individuo sólo en tanto que mi libertad se opone a otra libertad ( $\$ 22$ ), puedo afirmar también mi voluntad como tal sólo en oposición (Gegensatz) a otra voluntad.

$\S 49$ Afirmo la individualidad de mi voluntad en particular:

a) frente a la voluntad universal, no según la materia, sino según

la forma:

[149] Determino la materia de mi voluntad por la voluntad universal, a fin de que la voluntad de todos los demás esté condicionada por la forma de mi voluntad. Pues sólo la materia de mi acción (aquello que acontece en virtud de ella), no su forma (libertad del querer), depende de la voluntad universal.

Y a la inversa, no la materia, sino la forma de mi voluntad (libertad) condiciona la materia de la voluntad universal.

$\S 50$ Afirmo la individualidad de mi voluntad:

b) en oposición a la voluntad individual:

Mi voluntad se somete a la voluntad universal a fin de que no se someta a ninguna voluntad individual.

$\mathrm{O}$ : Me impongo la voluntad universal como ley a fin de que mi voluntad sea ley de toda otra voluntad.

$\S 51$ Precisamente así afirmo la individualidad de mi voluntad

c) en oposición a la voluntad en general.

Mi voluntad se somete a la voluntad universal para que su esfuerzo en general no sea opuesto a ningún otro esfuerzo, ni su querer en general a ningún otro querer; es decir, para que ella devenga potencia absoluta, ilimitable (\$ 45$)$.

[150] § 52 Por consiguiente, la ética no puede simplemente anular (aufheben) la individualidad de mi voluntad según la materia, sin afirmarla a la vez según la forma; $y$ a la ética, esto es, a la parte de la moral que exige universalidad de la voluntad según la materia, debe oponerse otra ciencia que afirme la individualidad de la voluntad según la forma.

§ 53 Esta ciencia admitida problemáticamente debe ser determinable por entero sólo en contraposición a la ética, y todos sus problemas deben poder ser deducidos a partir de esta antítesis.

§ 54 La ética exige que la voluntad individual sea idéntica a la universal. Ahora bien, la voluntad individual puede ser diferente de la voluntad universal sólo en cuanto está determinada materialmente ( $\$ 26$ ); luego tampoco se puede exigir la identidad de la voluntad individual con la universal sin anular la materia de la voluntad individual como tal, esto es, sin que yo deba obrar en contra de la voluntad individual según la materia. Pero que yo obre contrariamente a la voluntad individual sólo puede ser ordenado, exigido imperativamente (mediante un deber). 
§ 55 En cambio, no puede exigirse que obre conforme a la forma de la voluntad individual. Que yo soy en general y que soy quien soy, es la afirmación incondicionada que sirve de fundamento a todas las afirmaciones categóricas.

§ 56 La proposición que afirma la individualidad de la voluntad sería, así pues, un principio teórico, absolutamente categórico, si no se le opusiese en la ética un mandato que anula la voluntad individual como tal según la materia (\$ 54).

[151] $\$ 57$ Por consiguiente, esta proposición no puede afirmar simplemente la individualidad de la voluntad según la forma, sin afirmarla a la vez como mera posibilidad en relación con aquel mandato. Pues, de otro modo, debería afirmarla en relación con dicho mandato o bien como realidad o bien como imposibilidad. Pero ninguna de las dos alternativas puede tener lugar.

$\S 58 \mathrm{Si} \mathrm{la}$ afirmase mediante aquel mandato como realmente puesta, entonces la afirmaría como mandada. Pero la individualidad de la voluntad no puede en absoluto ser mandada ( $\$ 55)$.

$\S 59 \mathrm{Si}$ la afirmase como imposible en relación con este mandato, la afirmaría como simplemente anulada por el mandato mismo; lo que de nuevo es inconcebible (\$52).

§ 60 La proposición que afirma la individualidad de la voluntad es en sí y por sí misma una proposición categórico-teórica (¡Yo (Ich) soy Yo!). Pero la misma proposición, en tanto que la afirma en relación con el mandato que suprime (aufhebt) la individualidad de la voluntad según la materia, es una proposición problemático-práctica, que permite la individualidad de la voluntad sólo según la forma.

§ 61 Pero la ciencia admitida problemáticamente, que afirma la individualidad de la voluntad ( $\$ 52)$, debe efectivamente ser establecida en oposición a la ciencia que anula la individualidad de la voluntad ( $\$ 52)$; por consiguiente, incluso en aquella ciencia la individualidad de la voluntad puede afirmarse según la forma sólo como posibilidad práctica.

[152] § 62 Posible en general significa lo que no es en absoluto, pero que justo por eso no está bajo una determinada condición. Se llama real a lo que, ciertamente, es, pero precisamente por esta razón es sólo bajo una determinada condición. Lo que pierde lo posible en su carácter de existencia, lo gana en el de incondicionado, y lo que lo real gana en el de existencia, lo pierde en el de incondicionado.

§ 63 La posibilidad, pensada prácticamente (en relación con la ética), consiste en lo que (desde el punto de vista práctico) no es pura y simplemente, pero por esa misma razón tampoco está bajo la determinada condición de un mandato; la realidad, pensada igualmente desde un punto de vista práctico, consiste en lo que es, mas sólo bajo la determinada condición de un mandato (es sólo porque debe ser).

$\S 64$ Debo (soll) hacer lo que es prácticamente real; y lo que debo, es conforme al deber (pflichtgemässig), adecuado al deber. El deber es aquello que es simplemente porque debe ser.

$\S 65$ Lo que es teóricamente posible, puedo (kann) hacerlo. Lo que es prácticamente posible, me está permitido (darf) hacerlo. Lo que me está permitido se llama, según el uso común del lenguaje, justo (recht) en general, y la misma posibilidad práctica por la que algo deviene justo, se llama el derecho (das Recht) en general. Justo [Derecho, Recht] es lo que no es prácticamente real de modo necesario; pero precisamente por esta razón tampoco se halla bajo la determinada condición de un mandato (5). 
$\S 66$ Por eso debo hacer todo lo que constituye un deber, un mandato (\$ 64). Pero la proposición que únicamente puede enunciar un mandato es la que anula mi voluntad según la materia (\$ 54); ahora bien, mi voluntad es anulada según la materia por la voluntad universal; en consecuencia, constituye un deber todo lo que es conforme a la materia de la voluntad universal.

$\S 67 \mathrm{Me}$ está permitido todo lo que es justo, posible prácticamente ( $\$ 65)$. Pero la proposición que únicamente puede enunciar una posibilidad práctica es la que [153] afirma la individualidad de la voluntad según la forma (en oposición a la noindividualidad de la voluntad según la materia) (\$ 57). Por consiguiente, es posible prácticamente todo lo que afirma en mí la individualidad de la voluntad según la forma, o, puesto que la individualidad de la voluntad es la forma de la voluntad en general, es entonces posible prácticamente, esto es, justo, todo lo que es conforme a la forma de la voluntad en general o (lo que es lo mismo) a la forma de la voluntad universal.

$\S 68$ Así pues, la ciencia admitida problemáticamente arriba, que me enseña a afirmar la individualidad de la voluntad, podría ser sólo la ciencia del derecho en general, y el principio supremo de toda filosofía del derecho sería el siguiente:

Tengo un derecho a todo aquello mediante lo cual afirmo la individualidad de mi voluntad según la forma, o bien:

Tengo un derecho a todo lo que es conforme a la forma de la voluntad en general (sin lo que la voluntad debería dejar de ser voluntad).

$\S 69 \mathrm{La}$ ciencia del derecho (que durante mucho tiempo no estuvo separada de la moral y que hasta hoy, en lo que concierne a su relación con esta ciencia, estaba completamente indeterminada) se afirma, en consecuencia, única y exclusivamente en oposición a la ciencia del deber (6).

$\S 70$ En efecto, la voluntad en general puede devenir individual sólo en oposición a la voluntad universal, así como la voluntad universal es voluntad universal sólo en oposición a la voluntad individual. Sin esta oposición no habría más que una voluntad absoluta, que no podría llamarse ni individual ni universal.

[154] § 71 El problema de toda filosofía moral es el de una voluntad absoluta. Ésta puede alcanzarse en un mundo moral sólo mediante la unión de la suprema individualidad con la suprema universalidad de la voluntad. Una voluntad de todos comprendería a la vez la máxima libertad ilimitada y la máxima conformidad con la ley.

$\S 72 \mathrm{La}$ ética resuelve el problema de la voluntad absoluta haciendo la voluntad individual idéntica a la universal; la ciencia del derecho lo solventa haciendo la voluntad universal idéntica a la individual. Si ambas hubiesen cumplido perfectamente sus respectivos cometidos, dejarían de ser ciencias opuestas.

$\S 73$ Puesto que los principios fundamentales del derecho problemáticamente afirmativos son determinables sólo en oposición a la voluntad universal (el deber), pueden establecerse en la doctrina de los deberes sólo como principios categóricamente negativos. Sólo lo contrario de lo que la doctrina del derecho admite como posible, puede ser negado imperativamente en la doctrina de los deberes (que procede categóricamente). La posibilidad no puede afirmarse más que problemáticamente; pero categóricamente puede ser sólo negada.

$\S 74$ Luego en la ética el principio supremo de todo derecho sólo puede enunciarse negativamente: 
No te está permitido absolutamente nada que anule la individualidad de la voluntad según la forma; o bien no te está permitido absolutamente nada que anule la voluntad en general (según la forma).

[155] § 75 Estos imperativos negativos no pueden aparecer en modo alguno en la doctrina del derecho, porque en ella no puede presentarse ningún mandato (ni afirmativo ni negativo) (§55).

\section{ANÁLISIS DEL PRINCIPIO SUPREMO Y DEDUCCIÓN DE LOS DERECHOS ORIgINARIOS}

§ 76 Así como la filosofía teórica se eleva a la síntesis más alta posible a través de una serie de síntesis, la filosofía práctica, a la inversa, desciende hacia una tesis absoluta por una serie de análisis; y, así como el proceder de la filosofía teórica es sintético, el de la filosofía práctica debe ser analítico.

$\S 77$ Todos los derechos originarios deben ser deducidos analíticamente del concepto de derecho en general. El derecho en general, según la mera forma, es idéntico al derecho según la materia, pues la materia del derecho está determinada por la forma del derecho y no al revés.

\section{A}

$\S 78 \mathrm{Me}$ está permitido (darf) en general y me está permitido algo. Se puede así diferenciar entre materia y forma del estar permitido (Dürfen).

§ 79 La forma del estar permitido es la posibilidad práctica. Pero la posibilidad práctica no es sino la independencia de la voluntad individual respecto de la universal (porque sólo en virtud de la oposición a la voluntad universal puede determinarse algo como posibilidad práctica y, a la inversa, sólo en virtud de la oposición a la voluntad individual puede determinarse algo como imposibilidad práctica). Pero esto precisamente (la independencia respecto de la voluntad universal) [156] es la materia de todo derecho. El derecho, según la materia, no es sino lo que se produce independientemente, incluso en oposición a la voluntad universal, por la mera forma de la voluntad individual.

$\S 80$ La materia del estar permitido se encuentra entonces determinada por la forma del estar permitido, no a la inversa; y el principio supremo del derecho también podría expresarse así:

Es posible prácticamente todo aquello mediante lo que se afirma la posibilidad práctica en general (la individualidad de la voluntad según la forma); o bien:

Me está permitido todo aquello mediante lo que afirmo el estar permitido en general (según la forma).

§ 81 Si la materia del estar permitido no fuese determinada por su forma, no sería determinada por la voluntad individual (\$79), sino por la universal; pero lo último es contradictorio, puesto que el estar permitido en general sólo es pensable en contraposición a la voluntad universal ( $\$ 79)$.

$\S 82$ Si la materia del estar permitido se halla determinada por su forma, no puedo afirmar la forma del estar permitido sin afirmar a la vez su materia. 
$\S 83$ Por consiguiente, en tanto que tengo inmediatamente un derecho a la forma de mi voluntad, necesariamente tengo también, mediatamente, un derecho a su materia.

§ 84 En tanto que afirmo la materia de mi voluntad, afirmo también su forma, y a la inversa; y en tanto que es anulada la materia de mi voluntad como tal, también es anulada su forma.

[157] § $85^{3}$ La forma de mi querer en general es la libertad. Ahora bien, la libertad es el atributo de la voluntad en tanto que esta última es siempre el sujeto, nunca el objeto de una determinación, es decir, en tanto que no está determinada por la materia (el objeto) de su querer, sino que la materia está determinada por la voluntad (ihn) ${ }^{4}$.

[158] § 86 La libertad, considerada en general y en sí, no puede ser objeto de determinación alguna, ni siquiera objeto de una acción por la cual sería anulada. Por el contrario, la materia (el objeto) de mi libertad puede devenir nuevamente el objeto de una libertad opuesta, es decir, puede ser anulada como materia de mi voluntad.

$\S 87$ Por consiguiente, la forma de mi voluntad puede ser anulada sólo en tanto que se anula su materia, y la materia de mi voluntad no puede ser anulada sin que sea anulada a la vez su forma.

§ 88 Puesto que el problema de toda filosofía del derecho no es sino el de afirmar la forma de la voluntad individual, pero ésta no puede ser afirmada contra cada voluntad opuesta a ella más que mediante su materia, el principio inmediato de todo derecho, que se desprende de lo anterior, es el siguiente:

Te está permitido todo aquello por medio de lo cual afirmas la materia de tu voluntad, en cuanto está condicionada por su forma.

$\S 89 \mathrm{El}$ derecho a la materia vale, por consiguiente, sólo en cuanto está condicionado por el derecho a la forma; me está permitido afirmar la materia de mi voluntad sólo en cuanto afirmo a la vez la forma de la voluntad.

$\S 90$ La forma de la voluntad se afirma sólo en oposición a la materia de la voluntad, es decir, sólo en tanto que esta última es determinada absolutamente por ella, por consiguiente, en relación a ella [159] es absolutamente no-determinada (esto es, absolutamente determinable).

§ 91 Todos los problemas de la filosofía del derecho se refieren a la posibilidad de afirmar la forma de la voluntad. Luego todos deberían ser desarrollados a partir de esta oposición entre la forma y la materia de la voluntad.

$\S 92$ Si la materia de mi voluntad en relación a su forma debe pensarse como absolutamente no-determinada, esto es, como absolutamente determinable, entonces ella, como materia de mi voluntad, debe ser determinada o determinable exclusivamente por esta voluntad.

$\S 93$ De ahí se sigue que todos los problemas de la filosofía del derecho pueden ser deducidos a partir de la oposición de mi voluntad a cualquier otra causalidad determinante.

§ 94 La materia de mi voluntad como tal puede en general ser determinada sólo por la voluntad en general, a saber, o por la voluntad universal o por la voluntad individual.

$\S 95$ Por consiguiente, todos los problemas de la filosofía del derecho pueden deducirse de la oposición a la voluntad en general -a la voluntad individual y a la voluntad universal-.

[160] 


\section{AA. EL DERECHO EN OPOSICIÓN A LA VOLUNTAD UNIVERSAL}

§ 96 Someto la materia de mi voluntad a la voluntad universal sólo en tanto que la materia de la voluntad universal está condicionada por la forma de mi voluntad. Así pues, tendría un derecho contra la voluntad universal sólo en el caso de que su materia fuese contraria a la forma de mi voluntad.

§ 97 Pero la materia de la voluntad universal nunca puede ser contraria a la forma de mi voluntad. En efecto, lo que determina la materia de la voluntad universal es única y exclusivamente la forma de la voluntad individual. No parece entonces posible ningún conflicto entre la materia de la voluntad universal y la forma de la individual (esta dificultad es, sin duda, la razón por la que hasta ahora los teóricos del derecho natural no se atrevieron a hablar de un derecho contra la voluntad universal).

§ 98 En cambio, la forma de mi voluntad puede ser contraria a la materia de la universal. Pues aunque la voluntad universal, según la materia, esté determinada invariablemente por la forma de mi voluntad, sin embargo, ésta (la forma de mi voluntad) se halla absolutamente indeterminada (unbestimmt), y no es determinable en general por ninguna materia, ni siquiera por la materia de la voluntad universal. En realidad, no consiste sino en lo absolutamente indeterminado (Unbestimmtheit) respecto a toda la materia del querer, es decir, en que la materia de la voluntad está condicionada única y exclusivamente por la voluntad, y no a la inversa, la voluntad por la materia; en suma, en que obro como quiero y no quiero como obro.

[161] § 99 Ahora bien, suponiendo que obro como yo quiero y no como quiere la voluntad universal, suponiendo que la materia de mi voluntad esté determinada por su forma (la libertad), contrariamente a la voluntad universal, se plantea la cuestión de si mi acción es anulada por la voluntad del mundo moral o la voluntad del mundo moral por mi acción.

§ 100 Frente a la voluntad universal tengo un derecho sólo a la forma de mi voluntad. Así como, en oposición a la materia de la voluntad universal, tengo un derecho a la forma de mi voluntad, la voluntad universal tiene inversamente, en oposición a la forma de mi voluntad, un derecho a la materia de mi voluntad. La cuestión que se plantea es si puede hacer valer este derecho.

$\S 101$ La materia de mi voluntad está condicionada por su forma, y la materia no puede ser anulada sin anular a la vez la forma (§ 87). Por consiguiente, la voluntad universal no puede ejercer su derecho a la materia de la voluntad individual sin ejercer a la vez un derecho a su forma, esto es, sin anular mi derecho a ella.

§ 102 Pero la materia de la voluntad universal está determinada por la forma de la voluntad individual ( $\$ 34$ ). La voluntad universal como tal no puede querer que sea anulada la forma de mi voluntad ni, por consiguiente, su materia, en tanto que ella está condicionada por la forma de mi voluntad. De ahí se sigue que el derecho de la voluntad universal sobre la voluntad individual es un derecho imperfecto (unvollkommenes), porque no puede ejercerlo sin anular la voluntad en general y con ésta a sí misma.

$\S 103 \mathrm{Si}$ la voluntad del mundo moral es anulada por mi voluntad, lo es sólo según la materia, pues no podía determinar la forma de mi voluntad (§ 49); [162] luego mediante mi acción, en tanto que es contraria meramente a la materia de la voluntad universal, 
no puede anularse ninguna acción que pertenezca a la voluntad universal según la forma.

$\S 104$ Puesto que estoy autorizado (berechtigt) para [hacer] todo lo que no contradice la forma de la voluntad universal ( $\$ 67$ ), estoy entonces autorizado para anular la voluntad universal según la materia. Pero lo estoy únicamente en tanto que la materia de mi acción está condicionada por la forma de la voluntad individual, es decir, en tanto que no es contraria ella misma a la forma de la voluntad individual o, lo que es equivalente, a la de la voluntad universal.

$\S 105$ El principio "Frente a la voluntad universal me corresponde un derecho a la forma de mi voluntad" puede ser determinado como sigue:

I. Frente a la voluntad universal, tengo un derecho sobre la ipseidad (Selbstheit) de la voluntad, incluso según la materia, en tanto que así afirmo mi derecho sobre la ipseidad de la voluntad según la forma.

$\S 106$ Sin embargo, no puedo ponerme nunca en el caso de afirmar la individualidad (Individualität) de mi voluntad según la forma contra la voluntad universal. La voluntad universal, desde el momento en que aspirara (strebte) a anular, según la materia y la forma, cualquier voluntad, dejaría de ser voluntad universal. Lo es sólo en cuanto está condicionada por la voluntad individual.

$\S 107$ En consecuencia, este derecho a la individualidad de mi voluntad según la materia (§ 106) nunca puede hacerse valer contra la voluntad universal. En efecto, si hubiese algún derecho a anular una voluntad cualquiera según la materia y la forma, este derecho podría corresponderle sólo a una voluntad individual.

[163] § $108 \mathrm{El}$ problema expuesto anteriormente se transforma en el siguiente: ¿Le está permitido a una voluntad individual ser la ejecutora del derecho que, en lo que atañe a la materia de mi voluntad, le corresponde a la voluntad universal?

$\S 109$ Pero este problema nos conduce por sí solo al siguiente problema más general: $¿$ Puede acaso corresponderle a una voluntad individual un derecho contra una voluntad individual?

\section{BB. EL DERECHO EN OPOSICIÓN A LA VOLUNTAD INDIVIDUAL}

§ 110 Mi voluntad se somete a la voluntad universal para no subordinarse a ninguna individual (§ 50), esto es, afirmo mi individualidad pura y simplemente (schlechthin) en oposición a cualquier otra individualidad.

§ 111 Sólo la voluntad universal, no la individual, debe determinar la materia de mi voluntad. Así es establecido el principio:

II. Tengo un derecho a la materia de mi voluntad en oposición a cualquier voluntad individual.

$\S 112$ Puedo tener un derecho frente a cualquier voluntad individual ( $\$ 109)$ sólo en cuanto ésta se esfuerza (strebt) por anular mi voluntad, y el principio formal general, que afirma el derecho en oposición a la voluntad individual, es el siguiente: Una voluntad individual que se esfuerza por anular otra voluntad, y en la medida en que lo hace, es anulada absolutamente por ésta.

$\S 113 \mathrm{Si}$, por consiguiente, afirmo mi voluntad al anular la de otro, se presupone siempre que éste se esfuerza por anular la mía. [164] Ahora bien, la ley de la voluntad universal exige querer lo que todos los seres morales pueden querer $(\$ 45)$, por tanto, 
no es posible que las dos voluntades en conflicto sean conformes a la ley (gesetzmässig), sino que necesariamente ambas, o al menos una de ellas, deben ser contrarias a la ley (gesetzwidrig).

1. Primer caso: ambas son contrarias a la ley según la materia.

$\S 114$ Del principio anteriormente establecido, según el cual la materia de la voluntad universal está condicionada por la forma de la voluntad individual ( $\$ 34$ ), se siguen inmediatamente estos principios:

a. Puedo obrar en contra de la materia de la voluntad universal (la moralidad), sin obrar también en contra de la forma de la voluntad individual (la libertad); puedo anular la voluntad universal según la materia, sin anular la voluntad en general según la forma.

b. No puedo obrar contra la forma de la voluntad universal (la libertad individual), sin obrar a la vez contra la materia de la voluntad universal (la moralidad).

c. No puedo obrar conforme a la voluntad universal según la materia, sin obrar a la vez de acuerdo con su forma (la libertad de la voluntad en general).

d. Puedo obrar con arreglo a la forma de la voluntad universal (la libertad), sin obrar a la vez en conformidad con la materia de la voluntad universal (la moralidad).

$\S 115$ En la colisión (Collision) de voluntades contrarias a la ley, son posibles de nuevo dos casos:

a. Ambas son contrarias a la ley también según la forma; es decir, ambas persiguen anularse mutuamente.

[165] § 116 Tengo el derecho de anular absolutamente cualquier voluntad individual, en cuanto ésta se esfuerce por anular la mía. Por consiguiente, voluntades opuestas, que persiguen anularse recíprocamente, poseen también el derecho de anularse recíprocamente, esto es, ninguna de las dos tiene el derecho de afirmarse contra la otra.

$\S 117$ De donde resulta el principio:

$\alpha$. Acciones formalmente contrarias a la ley, en cuanto entran en colisión como tales, poseen un derecho recíproco una frente a la otra. Ambas están recíprocamente, una para la otra, fuera de la ley. Allí donde concurren sus voluntades opuestas, en su esfuerzo empírico, en el mundo de los fenómenos, las dos se anulan mutuamente si son iguales tanto respecto del poder (Können) como respecto del estar permitido (Dürfen).

b. Una de ellas es contraria a la ley también según la forma, y se esfuerza por anular la otra.

$\S 118$ Una voluntad que es contraria a la ley según la forma, lo es, precisamente por esto mismo, también según la materia ( $(114, b)$. Si fuera anulada sólo por ser contraria a la ley según la materia, entonces la forma del querer en ella estaría condicionada por la materia del querer; lo que es imposible (§ 90).

$\S 119$ Por consiguiente, una voluntad que es contraria a la ley según la forma, es anulada absolutamente, sin ninguna consideración, no obstante, al hecho de que es contraria a la ley en lo que atañe a su materia (materiale Gesetzwidrigkeit), luego sólo en tanto que se esforzaba por anular la voluntad de otro.

$\S 120$ Es anulada enteramente por la voluntad del otro, no en tanto que ésta es contraria a la ley según la materia, sino en tanto que es voluntad en general, sin ninguna consideración a la materia del querer.

[166] § 121 En consecuencia, también la cuestión arriba planteada (§ 108) debe ser simplemente negada. Una voluntad individual conforme a la ley nunca puede anular la 
que es materialmente contraria a la ley, porque jamás puede anularla sin convertirse ella misma en contraria a la ley según la forma y, precisamente por ello, también según la materia. Una voluntad individual nunca puede exigir el ejercicio (exequiren) del derecho de la voluntad universal sobre la materia de la voluntad individual.

$\S 122$ De aquí se sigue el principio:

$\beta$. Tengo un derecho sobre mi voluntad materialmente contraria a la ley frente a toda otra voluntad formalmente contraria a la ley; o bien: poseo un derecho frente a cualquier voluntad contraria a la ley, en tanto que de esta manera afirmo mi voluntad contraria a la ley (formalmente).

2. Segundo caso: sólo una de las dos voluntades es contraria a la ley según la materia.

$\S 123$ Ninguna voluntad puede ser conforme a la ley según la materia, sin serlo a la vez según la forma (\$114). Por consiguiente, la voluntad conforme a la ley nunca puede aspirar a anular la voluntad contraria a la ley materialmente.

$\S 124$ Así pues, si tiene lugar un conflicto entre la voluntad conforme a la ley y su contraria, la razón de ello no puede radicar en la primera. Sólo la voluntad contraria a la ley puede perseguir la supresión de la voluntad del otro.

$\S 125$ Por consiguiente, también la voluntad contraria a la ley (§ 112) es absolutamente anulada en el conflicto con la voluntad conforme a la ley, no en cuanto es materialmente contraria a la ley (contraria a la voluntad universal), sino en cuanto es formalmente contraria a la ley (opuesta a la voluntad individual).

[167] § 126 En cambio, la voluntad conforme a la ley se afirma en oposición (Gegensatz) a su voluntad contraria, no porque sea conforme a la ley materialmente, sino porque lo es formalmente. En este conflicto entre ambas voluntades, me pregunto acerca de la conformidad material de una de ellas con la ley ([legalidad material], Gesetzmässigkeit) sólo para demostrar así la contrariedad formal de la otra respecto a la ley ([ilegalidad formal], Gesetzwidrigkeit).

$\S 127$ De lo anterior resulta el siguiente principio:

$\gamma$. Tengo un derecho sobre mi voluntad (materialmente) conforme a la ley frente a cualquier voluntad (formalmente) contraria a la ley.

$\S 128$ Sólo en oposición a una voluntad individual puede haber un derecho sobre una voluntad conforme a la ley. Pues en oposición a la voluntad universal sólo existe un derecho (formal) sobre una voluntad contraria a la ley, y, en relación con ella, sólo un deber para con la voluntad conforme a la ley.

CC. El derecho en oposición a la voluntad en general

$\S 129$ En oposición a la voluntad individual y a la voluntad universal no me corresponde en general más que un derecho sobre acciones conformes formalmente a la ley. Pero allí donde ya no hay voluntad alguna, tampoco hay modo de obrar ni conforme ni contrario a la ley; mi voluntad deviene potencia absoluta e ilimitada.

$\S 130$ En el ámbito de la naturaleza cesa todo querer (Wollen). Este ámbito es el de la heteronomía. Por tanto, aquí ya no puede oponerse mi voluntad a ninguna otra, [168] y mi derecho sobre la naturaleza debe ser un derecho que afirmo en oposición a toda voluntad en general.

\$ 131 Manifiesto mi libertad por el solo hecho de dominar (herrschen) todo lo que es heterónomo (§ 6). Poseo un derecho a todo aquello por lo que afirmo mi libertad. Así se obtiene este principio: 
III. Tengo un derecho a afirmar, contra toda voluntad, la ipseidad de mi voluntad mediante un dominio ilimitado de la naturaleza.

$\S 132$ La autonomía (Autonomie) debe predominar absolutamente sobre la heteronomía. Todo lo que es objeto debe comportarse pasivamente frente a la espontaneidad ([autoactividad], Selbstthätigkeit) de un sujeto moral.

$\S 133$ Si todo objeto debe comportarse con absoluta pasividad frente a la autonomía, el objeto, en tanto que está determinado por la autonomía, ya no debe ser ulteriormente determinable por una autonomía contrapuesta (entgegengesetzte). Mi predominio sobre los objetos debe afirmarse absolutamente frente a toda otra voluntad.

$\S 134$ De lo contrario, se presupondría que el objeto no se comporta de modo absolutamente (schlechthin) pasivo frente a la autonomía, mediante la que está ya determinado. Si se ha comportado de modo puramente pasivo respecto a mi voluntad, es por ello $=0$ para cualquier otra voluntad. Deja de ser objeto para todo otro ser moral.

$\S 135 \mathrm{Si}$ los objetos en general no se comportasen de manera absolutamente pasiva frente a la libertad de la voluntad, no podría haber en realidad ningún conflicto de la libertad en relación con ellos. En efecto, si no fuesen absolutamente determinados por la libertad de un ser moral, ninguna acción libre podría sustraerlos, como objetos, a toda voluntad extraña (fremden), incluso permanecerían siempre determinables heterónomamente. Pero entre autonomía y heteronomía no puede haber ninguna colisión.

[169] § 136 Sólo porque la voluntad libre determina absolutamente los objetos, a la autonomía, en cuanto se refiere a un objeto espontáneamente determinado (selbstthätigbestimmtes), ya no se le contrapone la heteronomía del objeto, sino la autonomía del sujeto determinante (bestimmenden). Pero la autonomía, en el conflicto con la autonomía, o bien se anula absolutamente o bien se limita recíprocamente a las condiciones bajo las cuales puede subsistir la libertad de todos los seres morales.

§ 137 La autonomía absolutamente ilimitada se presenta sólo donde existe la mera naturaleza, esto es, donde ninguna acción de la voluntad libre ha determinado aún la naturaleza. Únicamente en el mundo físico como tal no puede haber para mí, en tanto que ser moral, ninguna resistencia ( $\$ 11$ ss.).

$\S 138 \mathrm{Mi}$ libertad es diferente de la libertad en general sólo por limitación. En consecuencia, allí donde mi libertad es ilimitada, es idéntica a la libertad en general, es decir, deja de ser libertad individual. Luego mi libertad, en tanto que se refiere a la espontánea determinación de los objetos, deja de ser libertad individual.

$\S 139$ Si mi libertad individual es idéntica a la libertad en general, toda exteriorización (Äußerung) de mi espontaneidad anula toda espontaneidad extraña. Mientras yo obro, y en la medida en que yo obro, no debe obrar ningún otro individuo; es decir, debe hallarse en estado pasivo. Mi voluntad, en tanto que es la mía, debe ser sagrada para todo el mundo moral.

$\S 140 \mathrm{Si}$, tras el análisis que hemos realizado del principio supremo del derecho, enumeramos todos los derechos individuales, encontramos los siguientes:

[170] 1. En oposición a la voluntad universal, el derecho de la libertad moral, esto es, el derecho a la plena libertad de la voluntad individual respecto de las acciones tanto materialmente conformes a la ley como de las materialmente contrarias a ella. 
2. El derecho en oposición a la voluntad individual, el derecho de la igualdad formal -el derecho a afirmar mi individualidad en oposición a cualquier otra (según la materia y la forma)-.

3. El derecho en oposición a la voluntad en general -el derecho sobre el mundo de los fenómenos, sobre las cosas, sobre los objetos en general, es decir, derecho natural en sentido estricto (Naturrecht im engern Sinn) (7)-.

\section{C}

$\S 141$ Finalmente, me está permitido no sólo hacer algo en general, sino todo aquello mediante lo que afirmo la individualidad de mi voluntad; tengo un derecho a cualquier acción por la que logro salvaguardar la ipseidad de mi voluntad.

$\S 142 \mathrm{Mi}$ voluntad puede ser limitada según la materia (a determinadas acciones) sólo por la voluntad universal. Ahora bien, la materia de la voluntad universal está ella misma condicionada por la forma de la voluntad individual (la libertad). Luego esta última no puede estar determinada a su vez por aquélla.

$\S 143$ Pero la forma de la voluntad individual estaría condicionada por la materia de la voluntad universal, si fuese dependiente de ésta en cuanto a su propia autoafirmación (Selbstbehauptung).

$\S 144 \mathrm{La}$ libertad, la forma originaria de la voluntad individual, debe retornar a su originaria ilimitación apenas [171] esté en juego su autoafirmación. Es potencia absoluta capaz de someter cualquier potencia que se le oponga. Todo, incluso la voluntad universal, se pliega ante la libertad del individuo cuando obra con vistas a su propia salvación (Rettung). La voluntad universal deja de existir tan pronto como está en juego la salvaguarda (Rettung) de la libertad.

$\S 145$ Poseo un derecho a toda acción con la que afirmo la ipseidad de la voluntad y, por consiguiente, también un derecho a anular toda acción incompatible con la ipseidad de mi voluntad.

§ 146 La ipseidad de la voluntad queda anulada en cuanto la forma de la voluntad (la libertad) esté condicionada por la materia de la voluntad (por aquello que quiero), y no a la inversa.

§ 147 Coaccionar (zwingen) a alguien, en el sentido más amplio del término, significa condicionar la forma de su voluntad por la materia. Esta definición comprende tanto la coacción física (externa) en el sentido restringido del término, como la coacción psicológica (interna).

$\S 148$ La coacción moral es una contradicción. No puede haber entonces más que un esfuerzo (Streben) por coaccionar moralmente a alguien. Este esfuerzo es definido mediante la coacción física o psicológica, y el principio universal para juzgar la coacción reza así: en todo individuo que te coaccione físicamente, debes presuponer un esfuerzo por coaccionarte moralmente.

§ 149 La coacción en general es, consiguientemente, un esfuerzo por anular la ipseidad de la voluntad. Ahora bien, estoy autorizado para realizar cualquier acción mediante la cual es afirmada la ipseidad de la voluntad, luego también para oponer semejante esfuerzo a todo esfuerzo tendente a coaccionarme. A toda coacción se contrapone otra coacción. 
[172] § 150 Afirmando la ipseidad de la voluntad, no afirmo otra cosa que mi derecho. Toda afirmación de mi derecho, frente a una voluntad contraria, es al mismo tiempo anulación de esta voluntad, es decir, coacción ejercida sobre ella. Mi derecho, en oposición a una voluntad extraña, deviene entonces necesariamente derecho de coacción (Zwangsrecht).

$\S 151 \mathrm{~A}$ la voluntad universal le corresponde meramente un derecho sobre la materia de mi voluntad. La materia de la voluntad universal está condicionada por la forma de la voluntad individual. Por lo tanto, el derecho de la voluntad universal sobre la materia de mi voluntad no puede ser un derecho de coacción (nadie puede ser coaccionado para que obre moralmente).

$\S 152$ Por el contrario, la voluntad individual tiene un derecho sobre su libertad incluso frente a la materia de la voluntad universal. Todos los derechos están comprendidos en el derecho originario a la forma de una voluntad, en el derecho a la libertad. Así pues, la voluntad individual no puede tener derechos sin afirmarlos todos, incluso contra la materia de la voluntad universal.

§ 153 La voluntad individual es anulada sólo en oposición a una voluntad individual (la voluntad universal nunca puede querer que una voluntad cualquiera sea anulada). Obrando sólo inmoralmente, obro sólo contra la voluntad universal, no contra la voluntad individual. Obro siempre como cualquier individuo en cuanto tal podría hacerlo. Mi acción inmoral como tal no puede ser anulada ni por la voluntad de otro individuo, dado que no me esfuerzo en contra de su [173] voluntad, ni por la voluntad universal, porque a ésta no puede corresponderle nunca un derecho de coacción sobre una voluntad cualquiera.

$\S 154$ Puesto que la materia de mi acción está siempre condicionada por su forma, todos los seres morales, en cuanto pueden querer la materia de mi acción, deben querer también su forma, y no viceversa. Pero si la forma de mi acción fuese anulada, al no poder querer todos los seres morales la materia de mi acción, entonces la materia de mi acción estaría condicionada por su forma, lo que es contradictorio.

$\S 155$ Sólo la forma de la voluntad es idéntica por doquier. Si, por consiguiente, la forma de mi voluntad es anulada por la voluntad de cualquier individuo, éste suprime con ello la forma de su voluntad.

$\S 156$ Sólo por la identidad de la forma de la voluntad deviene todo ser moral idéntico a mí; sólo por la libertad de su querer reconozco un ser semejante (gleich) a mí.

$\S 157$ Sólo en tanto que determina la materia de su voluntad por la libertad, deviene él un individuo. Pero precisamente porque determina la materia de su voluntad mediante la libertad, debe ser tan diferente de mí, respecto a la materia, como es idéntico a mí respecto a la forma.

§ 158 Luego si anula en él la forma de la voluntad, deja por eso mismo de ser idéntico a mí. Deviene un objeto para mí.

§ 159 Todo lo que es objeto para mí debe estar absolutamente determinado por mi esfuerzo. Lo relego a los límites (Schranken) del fenómeno y lo determino heterónomamente, mediante las leyes de la naturaleza.

[174] § 160 Así pues, todo ser que anula en mí la forma de la voluntad, deviene para mí mero objeto, entra en los límites del fenómeno y se torna un mero ser de la naturaleza.

§ 161 Por lo tanto, todo derecho deviene necesariamente para mí un derecho natural (Naturrecht), es decir, un derecho que afirmo según las solas leyes de la naturaleza 
(Naturgesetzen), y, en caso de conflicto respecto a este derecho, todo ser es para mí un puro ser natural (Naturwesen) (8).

$\S 162 \mathrm{El}$ derecho natural se destruye necesariamente él mismo en sus consecuencias (Consequenz) (en tanto que deviene derecho de coacción), esto es, suprime todo derecho. En efecto, es a la superioridad física (physische Übermacht) a la que se confía en último extremo la conservación del derecho.

§ 163 Es una exigencia de la razón que lo físico sea determinado por las leyes morales y que toda potencia natural esté ligada (im Bunde) a la moralidad. Por consiguiente, el derecho natural conduce necesariamente a un nuevo problema: el de hacer idéntica la potencia (Macht) física del individuo a la potencia moral del derecho, es decir, al problema de encontrar un estado (Zustande) en el que la fuerza (Gewalt) física siempre esté del lado del derecho. En cuanto nos ocupamos de la solución de este problema, entramos en el terreno de una nueva ciencia.

\section{POST SCRIPTUM}

El escepticismo (que en ninguna parte es tan peligroso como allí donde el interés y el egoísmo pueden pasar inmediatamente de los principios mismos a la aplicación), aliado al espíritu literal (Buchstabengeist) de presuntos filósofos, [175] constriñe a la ciencia a deducir sus principios de la manera más rigurosa, precisa y detallada posible, aunque, al proceder así, debieron sacrificarse enteramente la gracia de un discurso más fácil y la amenidad de una exposición natural y ágil. Por eso tienen tales empresas sólo un mérito efímero; una vez que se está cierto de los principios y se ha decidido al respecto entre los filósofos, constituye un deber y una necesidad presentarlos -si bien de una forma completamente diferente-también al pueblo (Volk). Este no debe pretender tomar parte en las investigaciones antes de que estén concluidas y suficientemente elaboradas para someterlas al juicio general y público. Abalanzarse sobre los filósofos y perseguirlos con calumnias e injurias a causa de sus fatigas, no podría venírsele a las mientes sino al populacho (Pöbel), que, rudo e incapaz de discernir como es, se ensaña contra todo lo que no comprende -aun cuando esto coadyuvara al bien común-, por el mero hecho de que de tal asunto no entiende nada.

Los presentes aforismos no aspiran a ser más que aforismos. Su comentario se lo reserva el autor tanto más cuanto que las recientes contribuciones del derecho natural (9), que no ha podido utilizar para este trabajo, le proporcionarán abundante material con miras a reflexiones más maduras así como múltiples ocasiones para desarrollar sus principios de una forma más completa.

\section{NOTAS}

(1) "Queremos juzgar hechos (Tatsachen) según una ley que no puede derivarse ni estar contenida en ningún hecho. ¿De dónde podemos tomar esta ley? ¿Dónde pensamos encontrarla? Sin duda, en nuestro Yo (Selbst), puesto que es imposible encontrarla fuera de nosotros; ciertamente en nuestro Yo (Selbst), en tanto que no está formado ni configurado por las cosas exteriores mediante la experiencia (pues aquél no es nuestro verdadero Yo, sino un añadido extraño), sino en su forma pura y originaria (reinen, ursprünglichen), en nuestro Yo tal como sería sin ninguna experiencia" (J. G. FICHTE, Beitrag zur Berichtigung des Urteiles des Publikums über die Französische Revolution, 
1793-1794, J. G. FICHTE. Gesamtausgabe (GA), I/1, Frommann, Stuttgart, 1964, pp. 218 ss.). Aunque aquí hemos traducido Selbst como Yo, en los parágrafos siguientes (a partir del § 31) hemos optado por ipseidad para Selbstheit, y no por Yoidad o Egoidad (Ichheit), expresión esta última que proliferará en las versiones fichteanas de la Doctrina de la Ciencia, y no tanto en los Escritos de Revolución. En las Cartas sobre criticismo y dogmatismo, Schelling empleó ya ese término: "Según el criticismo, mi destino consiste en el esfuerzo en pos de la ipseidad, la libertad incondicionada y la actividad ilimitada" (F. W. J. SCHELling. Historisch-kritische Ausgabe, 1/3, p. 106). Es evidente que la terminología fichteana ha desplazado ya en las Cartas a la estrictamente kantiana, y que la propiamente schellinguiana comienza a solaparse a aquélla, atisbándose los primeros conatos de apostasía del fichteanismo kantiano.

(2) Über die Lehre des Spinoza in Briefen an den Herrn Moses Mendelssohn, 2. vermehrte Ausg., Breslau, 1789; Jacobi Werke, IV/1, edición a cargo de F. ROTH Y F. KOPPEN, Wissenschaftliche Buchgesellschaft, Darmstadt, 1968, p. 211: "Es por la fe (Glauben) por lo que sabemos que tenemos un cuerpo y que fuera de nosotros hay otros cuerpos y otros seres pensantes. ¡Una revelación (Offenbarung) verdadera, maravillosa! Pues sentimos solamente nuestro cuerpo, constituido (beschaffen) así o de otro modo, y, en tanto que sentimos que está constituido así o de otro modo, nos apercibimos no únicamente de sus modificaciones, sino también de algo enteramente diferente, que no es ni sentimiento ni pensamiento, nos apercibimos de otras cosas reales, y esto con la certeza con la cual nos apercibimos de nosotros mismos; sin un tú el yo es imposible. Por consiguiente, así obtenemos todas las representaciones, sólo por los modos de constitución (Beschaffenheiten) que suponemos, y no hay ningún otro camino para llegar al conocimiento real, puesto que, cuando la razón engendra objetos, produce quimeras (Hirngespinste)". Cf. p. 72: "En mi opinión, el mayor mérito del investigador es desvelar lo que existe (Dasein) y revelarlo (offenbaren). La explicación es para él un medio, un camino conducente a la meta, un fin muy próximo, pero jamás el fin último. Su fin último es lo que no puede explicarse: lo insoluble, inmediato, simple". Cf. p. 223: "No podemos demostrar más que similitudes (Ähnlichkeiten), puesto que la demostración es progreso a través de proposiciones idénticas; y toda demostración presupone algo ya demostrado, cuyo principio es la revelación".

(3) J. J. ROUSSEAU, Du contract social ou principes du droit politique, Amsterdam, 1762. La esencia del pacto social reside en lo siguiente: "Cada uno de nosotros pone en común su persona y todo su poder bajo la suprema dirección de la voluntad general; y nosotros recibimos corporativamente (en corps) a cada miembro como parte indivisible del todo" (Oeuvres completes, Pléiade, París, 1964, III, p. 361; ed. cast. Alianza Editorial, Madrid, 1980, p. 23). Cf. KANT: “Obra de tal modo que la máxima de tu voluntad pueda valer siempre, al mismo tiempo, como principio de una legislación universal” (Crítica de la razón práctica, AK, V, p. 30; ed. cast. Espasa-Calpe, Madrid, 1975, p. 50).

(4) ROUSSEAU: "Con frecuencia hay mucha diferencia entre la voluntad de todos y la voluntad general; ésta sólo mira al interés común, la otra mira al interés privado, y no es más que una suma de voluntades particulares: pero quitad de estas mismas voluntades los más y los menos que se destruyen entre sí, y queda por suma de las diferencias la voluntad general" (Oeuvres completes, III, p. 371; ed. cast., p. 35).

(5) K. L. REINHOLD, Briefe über die kantische Philosophie (Cartas sobre la filosofía kantiana), II, Leipzig, 1792: "El derecho (Recht) es lo que es posible mediante (durch) la libertad de la voluntad mediada por (vermittelst) la ley moral. Este género comprehende 
bajo sí las dos especies siguientes: aquello que es únicamente (einzig) posible, esto es, necesario, mediante la libertad mediada por la ley moral, y aquello que es (no únicamente, sino sólo) meramente (bloß) posible mediante la libertad mediada por la ley moral. Lo último es el derecho en sentido estricto (engeren), lo primero el deber".

J. G. FICHTE, Beitrag: "Lo que esta ley nos ordena se llama en general justo, un deber; lo que nos prohíbe, injusto, contrario al deber. Debemos hacer lo primero, no debemos hacer lo segundo. En cuanto seres racionales estamos sometidos absolutamente y sin ninguna excepción a esta ley; por consiguiente, no podemos (können) estar, en cuanto tales, sometidos a ninguna otra; allí donde ella se calla, no estamos sometidos a ninguna ley, nos encontramos en la esfera de lo que nos está permitido (dürfen). Todo lo que la ley no prohíbe, nos está permitido hacerlo. Tenemos un derecho a todo lo que nos está permitido hacer, porque este estar permitido es legal" (GA 1/1 p. 220).

En Del Yo como principio absoluto de la filosofía (1795) aparece ya una alusión al derecho natural, irrelevante en el contexto de este breve escrito, aunque importante por el alineamiento de Schelling con Kant y Fichte en su crítica al eudemonismo como fundamento de legitimidad de un Estado: "El concepto de derecho en general, y el sistema entero del derecho natural, se basa en el concepto de la posibilidad práctica...; el concepto de deber, y el sistema entero de la ética, se basa, sin embargo, en el concepto de la realidad práctica". Para el ser finito el derecho depende del deber, y "el fin supremo hacia el cual tienen que apuntar todas las constituciones políticas (que están fundadas en el concepto de deber y derecho) puede ser únicamente la identificación de los derechos y deberes de cada individuo particular" (F. W. J. Schelling. Historisch-kritische Ausgabe, 1/2, Frommann, Stuttgart, 1980, pp. 164-165).

(6)REINHOLD: "en el significado determinado más exactamente, derecho tiene que designar precisamente lo contrario del deber; por el deber es limitado siempre el arbitrio respecto al impulso egoísta; por el derecho es abandonado siempre a sí mismo" (II, p. 201).

(7) KANT, Über den Gemeinspruch (1793): "Por tanto, el estado civil, considerado simplemente como estado jurídico, se funda en los siguientes principios a priori: 1) La libertad de cada miembro de la sociedad, en cuanto hombre. 2) La igualdad de éste con cualquier otro, en cuanto subdito. 3) La independencia de cada miembro de una comunidad, en cuanto ciudadano. Estos principios no son leyes que dicta el Estado ya constituido, sino más bien las únicas leyes con arreglo a las cuales es posible el establecimiento de un Estado en conformidad con los principios racionales puros del derecho humano externo en general" (AK, VIII, p. 290; ed. cast. Teoría y práctica, Tecnos, Madrid, 1986, p. 27). Y más adelante añade lo siguiente sobre el tercer principio: "Ahora bien, aquel que tiene derecho a voto en esta legislación se llama ciudadano (citoyen, esto es, ciudadano del Estado, no ciudadano de la ciudad, bourgeois). La única cualidad exigida para ello, aparte de la cualidad natural (no ser niño ni mujer), es ésta: «que uno sea su propio señor (sui iuris) y, por tanto, que tenga alguna propiedad (incluyendo en este concepto toda habilidad, oficio, arte o ciencia) que le mantenga; es decir, que en los casos en que haya de ganarse la vida gracias a otros lo haga sólo por venta de lo que es suyo, no por consentir que otros utilicen sus fuerzas; en consecuencia, se exige que no esté al servicio -en el sentido estricto de la palabra- de nadie más que de la comunidad" (AK, VIII, p. 295; ed. cast. p. 34).

(8) REINHOLD: "El derecho natural (natürliche Recht), o derecho natural (Naturrecht) en tanto que objeto de la ciencia de este nombre, es la facultad moral de tratar a otros 
hombres según meras leyes naturales (Naturgesetzen), en la medida en que el mismo depende del trato no conforme al derecho (unrechtmässigen) según estas leyes" (II, p. 217).

(9) Entre ellos conviene destacar la reseña que realizó Fichte de La paz perpetua de Kant (Philosophisches Journal, IV/1, 1796, p. 81-92; GA 1/3, pp. 221-228) y la magna obra de aquél Fundamento del derecho natural según los principios de la doctrina de la ciencia, cuya parte primera apareció en 1796 (GA 1/3, pp. 311-460), amén de los citados en la Introducción.

\section{NOTAS}

1. ¡Esta es la expresión exacta que conviene aquí! Sobre su sentido y contenido el autor se explicará en otro lugar. No le puede parecer extraña a quien haya comprendido a Jacobi (2).

2. El hecho de que un ser que me sea semejante por su aspecto exterior se deje determinar por mí según un fin (Zweck) y una intención (Absicht), no prueba aún que tengo un hombre ante mí; pues podría no ser más que un animal dócil. Esta afirmación es corroborada por la experiencia que muestra que los que en sus pretensiones no encuentran nunca oposición en la voluntad de otro, acaban perdiendo todo respeto por esta especie sumisa y, finalmente, por la humanidad misma. Sólo cuando me dirijo a la voluntad de otro y éste rechaza mis exigencias con un categórico «jno quiero!» o pone en venta su libertad sólo al precio de la mía, reconozco que tras ese rostro posee su morada la humanidad y en ese pecho vive la libertad.

3. [Acerca de la relación de esta deducción con recientes investigaciones sobre este mismo asunto, se encontrará una declaración del autor al final del artículo. Por nuestra parte, tan sólo debemos indicar que este escrito nos fue enviado hace ya un año y medio, y que, por sus originales opiniones, incluso tras la aparición de nuevos trabajos, no podemos considerarlo en absoluto obsoleto. Los editores].

4. Lo que se sigue de esta proposición para la teoría de los contratos, etc., lo dejo al juicio de mis lectores. Sólo haré una observación. Puesto que la materia de mi voluntad nunca puede determinar la voluntad misma, y esta última escapa al infinito a toda determinación objetiva, para asegurar un contrato sería necesaria una serie infinita de contratos, de los que cada uno confirmaría el precedente, pero él mismo estaría a su vez necesitado de una nueva confirmación. Que esté de acuerdo conmigo mismo en esta serie infinita de contratos no es sino una mera exigencia de la moral. Pero respecto a la cuestión de saber si, mientras la moralidad -el esfuerzo en pos de la concordancia consigo mismo- no santifique los contratos, tenemos en el egoísmo (Eigennutz) de los hombres -al que se apela de buen grado tan pronto como se encuentra ventajoso hacerlo- una garantía de nuestros contratos más segura que en aquella serie infinita de libres decisiones, mis lectores pueden juzgar. 